\title{
Composição: Ensaio em 03 Movimentos
}

\author{
MILENA SZAFIR
}

Milena Szafir é pesquisadora e realizadora em estéticas [neo-]cinematográficas. Designer Audiovisual formada (graduação, mestrado e doutorado) pela USP, onde foi monitora nos Laboratórios de Fotografia (revelação e ampliação), de Vídeo (edição) e responsável pelo CineFau (cineclube universitário). Professora em artes e cinema, orienta as bolsas "Projet'ares Audiovisuais" (PROGRAD, SECULT-ARTE) e o Coletivo Artístico [Grupo de Pesquisas] "Intervalos \& Ritmos" [\#ir!]. Co-coordena o "Zootropo-Grupo de Estudos em Animação e Motion Graphics" (CNPq), "Alice, work in progress" (Experimentações Sonoro-Videográficas para Fulldome, Labinter) e "Montagem Audiovisual: experiências e reflexões" (SOCINE). email: profmilena@manifesto21.tv AFILIAÇÃO: Universidade Federal do Ceará, (ICA- UFCE), Fortaleza CE , Brasil 


\section{- RESUMO}

O estado-da-arte da montagem audiovisual é compreendermos a imagem em movimento como design. Termos como ritmo, métrica, composição e intervalo são originalmente parâmetros instituídos (e operacionalizados) pela teoria e linguagem musical. Essse ensaio tenta um breve caminhar sobre banco-de-dados, memória, remix (nas suas vertentes com e sem capslock) e talvez uma deriva sobre as artes audiovisuais: dramaturgia da forma, grafismo, tipografia e cinema (experimental, de filme-ensaio, found footage ou sci-fi). Trata-se, enfim, de uma flaneurie, um perambular ensaístico sobre os modus operandi das estéticas videográficas afim de tornar-se composição, aqui em brevíssimos três movimentos. Ou, deveríamos dizer, três movimentos para um ensaio sobre composição? Ou, ainda, uma composição de três movimentos sob ensaio? Tal qual o choque na montagem eisensteiniana, a páthos é avessa ao lógos. Aesthesis nos fala sobre sensações, aquilo que a razão não consegue definir por completo (ou por complexo).

\section{PALAVRAS-CHAVE}

Montagem, estética, Pathosformeln, cinético, artes audiovisuais.

\section{ABSTRACT}

The state-of-art of moving image is to understand it became design. Terms such as rhythm, metre (metric), composition and interval are originally established terminologies of the musical language. This essay tries a brief walking through database, memory, remix (and the different meanings between in it when its on first caps lock character) - maybe a drift on audiovisual arts: a dialectic approach to film form, graphics, typography and cinema (the experimental ones, the found footage and essay-film or the sci-fi ones). In short, it is a flanerie, a strolling essay on the video aesthetics procedures in order to become a composition, in its current three movements. Or, should we say three movements forward an essay on composition? Or, maybe, could be a composition with three movements in the process of essay? Like "the collision" in Eisenstein montage theory, pathos is averse to logos. Aesthesis speaks to us on sensations, those things which reason couldn't whole (composite/ composed of) define.

\section{KEYWORDS}

Design, editing, aesthetics, motion graphics, Black Mirror. 


\section{\#work-in-progress}

Meu ponto de vista é o da estética. [...] É sabido que Platão distinguia as artes úteis, que tomavam os processos da natureza por modelo e a ela se adaptavam para em proveito do próprio homem, e as inúteis como a pintura - e a música. [...] Não esperem que eu tome partido contra as técnicas. Muito pelo contrário, julgo que frente a elas, os arquitetos e os artistas viram ampliado o seu repertório formal assim como se ampliaram seus meios de realizar." (ARTIGAS, 1967)

Após diversos anos de experimentações com filme, em 1965 eu descobri que 'Cinético' [cinemático] era uma 'expressão' que significava mais do que 'montagem criativa' (a manipulação do espaço-tempo; inventividades metafórica-imagísticas) ou 'câmera-sensitível' (movimentos expressivos de câmera, enquadramento, tonalidade composicional etc). Porque, em cada uma dessas instâncias, 'Cinético' significava 'tratamento cinemático' de um 'ente' não-cinematográfico. Então, eu comecei a olhar para as atuais materialidades e procedimentos de minha mídia, naquilo que elas possuem de mais básico e óbvio, para a questão do 'ente' sem si e em como apropriar-se de seus princípios estruturais como um todo. (SHARITS, 1978; tradução nossa)

Entre a Montagem Cinematográfica, as Estéticas Videográficas e o Design Audiovisual, o presente artigo tenta delinear (ou sintetizar, a convite da curadoria) uma breve 7 a versão dos recentes ensaios que venho desenvolvendo (muitos deles apresentados em congressos no Brasil e exterior) ao longo desses últimos três anos e meio após a defesa da tese "Retóricas Audiovisuais 2.1 [...]" (2011-2015). Lembramos que "movimento" é o termo utilizado na linguagem musical para as divisões em uma composição. Assim como "ritmo" e "intervalo", caros à teoria da montagem cinematográfica desde seus tempos silenciosos, são conceitos originários também da música.

Todas as vanguardistas formas, técnicas e imagens modernas encontram-se agora armazenadas nos bancos-de-memória computadorizados de nossa cultura para acesso instantâneo. (HUYSSEN apud MANOVICH, 2007; 2008-2013; nossa tradução')

Ao longo desse curto texto introdutório² (2007), Manovich repete cinco vezes uma mesma frase de Huyssen publicada em 1986. "Bancos de memória computadorizados"3 refere-se àquilo que, duas décadas depois, denominamos (MANOVICH, 2001; SZAFIR, 2010) "banco-de-dados":

\footnotetext{
${ }^{1}$ No original: "All modern and avantgardist techniques, forms and images are now stored for instant recall in the computerized memory banks of our culture." Citação presente nas traduções ao português do livro Software Takes Command e do artigo "After Effects, or Velvet Revolution", conforme realizadas pela autora do presente ensaio (em processo para publicação).
} 
Sua análise é certeira - exceto que esses 'bancos de memória computadorizados' não se tornariam lugar-comum pelos demais 15 anos [1986-2001]. (...) Em resumo, na metade dos anos de 1980 nenhum de nós ou qualquer outra produtora audiovisual tinha algo parecido com os 'bancos de memória computadorizados' imaginados por Huyssen. E, claro, o mesmo era verdadeiro aos artistas visuais que eram associados ao pós-modernismo e às ideias de pastiche, collage e apropriação. (MANOVICH, 2007; nossa tradução ${ }^{4}$ )

Assim, no atual labirinto dos multiálogos audiovisuais - entre cine e ruído nas tele-redes como um retorno às câmera-stylo em movediços diálogos - não se trata de recapitularmos a imagem em movimento afim de concluí-la. Tampouco de simplesmente reafirmarmos o cinema como arqueologia das mídias - as gestualidades entre o analógico, eletrônico e o digital. O estado-da-arte da montagem é compreendermos a imagem em movimento como design - projetares do audiovisual que engramatizam nossas memórias na amnésia dos tempos em banco-de-dados total. Trata-se, então, de desdobrarmos as artes audiovisuais como estéticas videográficas da montagem em todos os seus sentidos, sensações e dispositivos. Buscarmos, portanto, descobrir uma gama cada vez maior de possibilidades muitas vezes ainda não percebidas nas multiplicidades dessa forma que pensa - um pensamento que forma - em fluxo (in)constante a interfacear cotidianamente nossas relações sociais. Quais seriam tais estéticas de montagem nas artes audiovisuais?

Parafraseando o professor Artigas (1967), é sabido que Platão distinguia as artes úteis - que tomavam os processos da natureza por modelo e a ela se adaptavam em proveito do próprio homem - das inúteis (como a pintura e a música). Leonardo DaVinci desenhou como técnico e desenhou como artista. Procurou uma composição onde nada fosse arbitrário. Maneira de aproprição do conhecimento científico para informar a sensibilidade criadora. No fundo, escolhi para começar essas considerações para relembrá-los sobre o conflito histórico entre a técnica e a arte. É esta, aliás, a tese que pretendo experimentar aqui, aproveitando a oportunidade para tecer considerações em torno do desenho - do projetar (to design) -, linguagem da arte e da técnica. Assim, "design" - como palavra, traz consigo um conteúdo semântico extraordinário e pode vir a ser uma das formas novas de pensamento (reflexão) sobre as atividades superiores da sociedade.

Tentarei, portanto, operar através de uma ciência dos intervalos nessa arqueologia (ou cartografia) da montagem para averiguarmos as tangenciais technés

\footnotetext{
$\overline{2}$ Introdutório porque publicado em formato curto-artigo de nove páginas (2007). Manovich finaliza em 2008 seu rascunho ao livro "Software Takes Command" (que será publicado na forma impressa apenas em 2013). Introdutório, ainda, porque o título do artigo é o nome do software da Adobe em comunhão ao termo - políticoestético - "Velvet Revolution". No rascunho, o título disponibilizado ao capítulo referente era "Como o Cinema torna-se Design" e, finalmente, no livro impresso transforma-se em "Media Design". O trecho citado acima possui a seguinte continuidade adversativa: "Mas a mesma memória que armazena todas as artes prémodernistas também armazena os códigos, os gêneros e as globais imagens tanto das culturas populares como da cultura de massa moderna." (nossa tradução). No original: "But the same memory also stores all of premodernist art as well as the genres, codes, and image worlds of popular cultures and modern mass culture".

${ }^{3}$ Parágrafos primeiro, segundo, quarto (duas vezes) e décimo.

${ }^{4}$ No original: "His analysis is accurate - except that these 'computerized memory banks' did not really became commonplace for another 15 years. [...] In short, in the middle of the 1980 s neither we nor other production companies had anything approaching the 'computerized memory banks' imagined by Huyssen. And of course, the same was true for the visual artists who were then associated with postmodernism and the ideas of pastiche, collage, and appropriation. [...]". Traduções ao português do livro Software Takes Command e do artigo "After Effects, or Velvet Revolution", conforme realizadas pela autora do presente ensaio (em processo para publicação).
} 
desses modus operandi que, como estética, são provavelmente geradores de alguns estilos "geracionais". Assumo, ainda, que não pretendo aqui esgotar qualquer problema: tais aproximações, que a cada dia têm se apresentado mais desafiadoras, servem apenas para compartilharmos a parte descoberta de um iceberg.

\section{Movimento\#1}

"O que se passa na ilha-de-edição? É comparável isso a um experimento científico?" (FAROCKI, 1995)

Em "Schnittstelle"5, Harun Farocki elabora uma retórica audiovisual sobre a organização (e permutação a la Turing) das imagens em movimento, como são trabalhadas a partir da perspectiva do próprio realizador que performa para a câmera como um engenheiro de maquinarias. Trata-se de convidar o espectador a pensar agora como um montador em sua mesa de edição. Nessa instalação, Farocki nos apresenta alguns gestos de montagem característicos dos dispositivos midiáticos audiovisuais à época: vemos os controladores, as fitas, os decks, os monitores, os botões de corte... Acima de tudo, o que Farocki traz à tona, portanto, é o realizador podendo ser visto em seu habitat de trabalho, em seu projetar áudio-visual - como um designer -, tal como o fez Godard em "Roteiro do Filme Paixão" (SZAFIR, 2015). Talvez numa alusão a Vertov (em vista de seu filme-manifesto a uma "linguagem universal", 1929), Godard e Farocki realizaram obras-sistemas metalinguísticos sobre seus gestos de montagem. Discutem também o procedimento próprio (suas lógicas) na construção do jogo de imagens e sons, as gestualidades de cada qual em seu palco-dispositivo-aparato de escritura.

Ou seja, como o realizador - montador - organiza e manipula suas imagens (seus banco-de-dados)? Por um lado, trata-se de demonstrarmos um processo de pensamento concomitante à forma artística e, por outro, que esse pensar é ele próprio feito dentro de um objeto de reflexão que atravessa os significados fílmicos e eletrônicos. Do alemão, Schnitt significa corte, amputação, se(c)ção; Stelle significa lugar, sítio, local, repartição. "Schnittstelle" seria, portanto, o lugar de corte, a ilha de amputação. Em termos de informática a tradução que o dicionário nos traz para a junção das duas palavras é interface. É dessa maneira que o título em si nos traz os inseparáveis caminhos da poética e da techné (BLÜMLINGER, 2004). Farocki nos apresenta processo, procedimentos e reflexões nas ilhas-de-edição (videográfica e moviola). Trata-se de uma organização espaço-temporal do material imagético e a combinação da representação digital e (paradigmaticamente) analógica entre os gestos manuais do artista frente às questões da materialidade da própria imagem; na película "o corte é real" (sic) enquanto no vídeo é imaginário:

Ao se trabalhar com a película ao invés do vídeo [...] na mesa de edição eu coloco a ponta de meu dedo sobre a imagem ou o som que está a correr, afim de sentir o corte ou a cola, [vemos em um dos vídeos a imagem com enquadramento em close-up da mão do realizador-montador que mexe os dedos fazendo com que suas digitais se

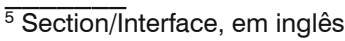


encontrem, polegar e dedo anelar sentem suas peles se tocarem] antes mesmo de ver o corte ou escutá-lo [a mão retorna à película em movimento. Em corte seco, a imagem é alterada. Agora, novo primeiro plano da mão performando tendo um televisor - monitor em tela azul ao fundo enquanto as digitais do polegar e dos demais dedos se encontram] Esse é um gesto que india 'percepção fina' - de precisão ou 'sensitiva'. A mão quase não tem qualquer contato com o objeto, mas o percebe em seu nada, no seu vazio. [a imagem corta novamente para um close-up de um controlador videográfico, mesa-de-edição eletrônica. Focado nos botões e desfocando ao fundo o 'disco' do controlador] Quando se trabalha com vídeo, eu não toco a fita, eu somente aperto botões. Uma outra atividade para as digitais. [Aos 04min.37seg. a imagem do outro vídeo - segundo monitor - é novamente alterada para aquela gravação-performance da mão frente ao monitor em azul. No primeiro monitor, a nova imagem é composta de duas mãos contando dinheiro] Aqui temos o gesto de contar dinheiro, que é provavelmente feito dessa maneira porque nós precisamos da delicadeza das digitais para contarmos [...] com a necessária precisão. (FAROCKI, 1995)

Remix - então com letra maiúscula - visava compreendermos uma viagem pelas gestualidades da composição audiovisual (estéticas de montagem entre o vídeo-remix e o filme-ensaio pensadas desde/para/na produção online). Sabemos que o filme-ensaio e o vídeo-remix co-existem, também, a partir de um nível metacrítico, destacando - na montagem - o aspecto 'plástico' da imagem. A montagem dialógica-discursiva através do jogo de símbolos - o que envolve uma disposição erudita considerável, pois aqui se trata de investigar discussões que atravessam no mínimo dois mil anos (se tomarmos a "Arte Poética" e a "Arte Retórica" como pontos de partida) - é a característica primordial de ambos os 'gêneros', ou extra-gêneros. Nas artes do fazer audiovisual, portanto, Remix significa que seus gestos de montagem caminham através das lógicas de linguagens que permeiam distintas estéticas videográficas.

Se a techné é o encontro do projetar (to design) com a poética que se vislumbra a uma era de jogos inter-conectados, qual o papel da escrita 6 audiovisual como uma forma estético-dialógica?

Ao longo desse percurso sobre as superfícies (membranas) onde se dão o online database, remix e montagem da imagem em movimento nesse início de século, verificamos ao longo dos últimos anos a importância (ou urgência) em retornarmos às nossas origens formativas de criação para as trabalharmos junto aos estudantes de cinema e audiovisual. Assim, didaticamente estamos a trabalhar as análises críticas audiovisuais desde questões de design gráfico com foco nos processos-experimentações do motion graphics em comunhão à literatura fantástica, aos gêneros de ficção científica e estudos de estética.

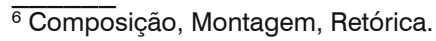

ouvirouver Uberlândia v. 14 n. 2 p. 340-360 jul.|dez. 2018 


\section{Movimento\#2}

Depois da tempestade 'a favor da montagem' e da batalha 'contra a montagem', devemos voltar a abordar esse problema com maior simplicidade. [...] Afinal, por que usamos a montagem? [...] propriedade [própria da montagem] consiste no fato de que dois pedaços de filme de qualquer tipo, colocados juntos, inevitavelmente criam um novo conceito, uma nova qualidade, que surge da justaposição. Esta não é, de modo algum, uma característica peculiar do cinema, mas um fenômeno encontrado sempre que lidamos com a justaposição de dois fatos, dois fenômenos, dois objetos. (EISENSTEIN, 2002)

"Fórmulas da paixão", Pathosformeln, é um conceito chave no método warburguiano de reescritura à história da arte ocidental. Warburg compreendeu ${ }^{7}$ que gestos característicos das emoções - e também geradores de paixão, afecções - se repetem e se perpetuam nas artes, como uma persistência sintomática das formas (DIDI-HUBERMAN, 2013). Os gestos que se repetem nas imagens - e que permeiam nosso inconsciente sócio-cultural como engramas hereditários da memória (GINZBURG, 2014) - são modelos corporais (uma corporeidade do sintoma) que se tornam então formas disparadoras de conteúdo.

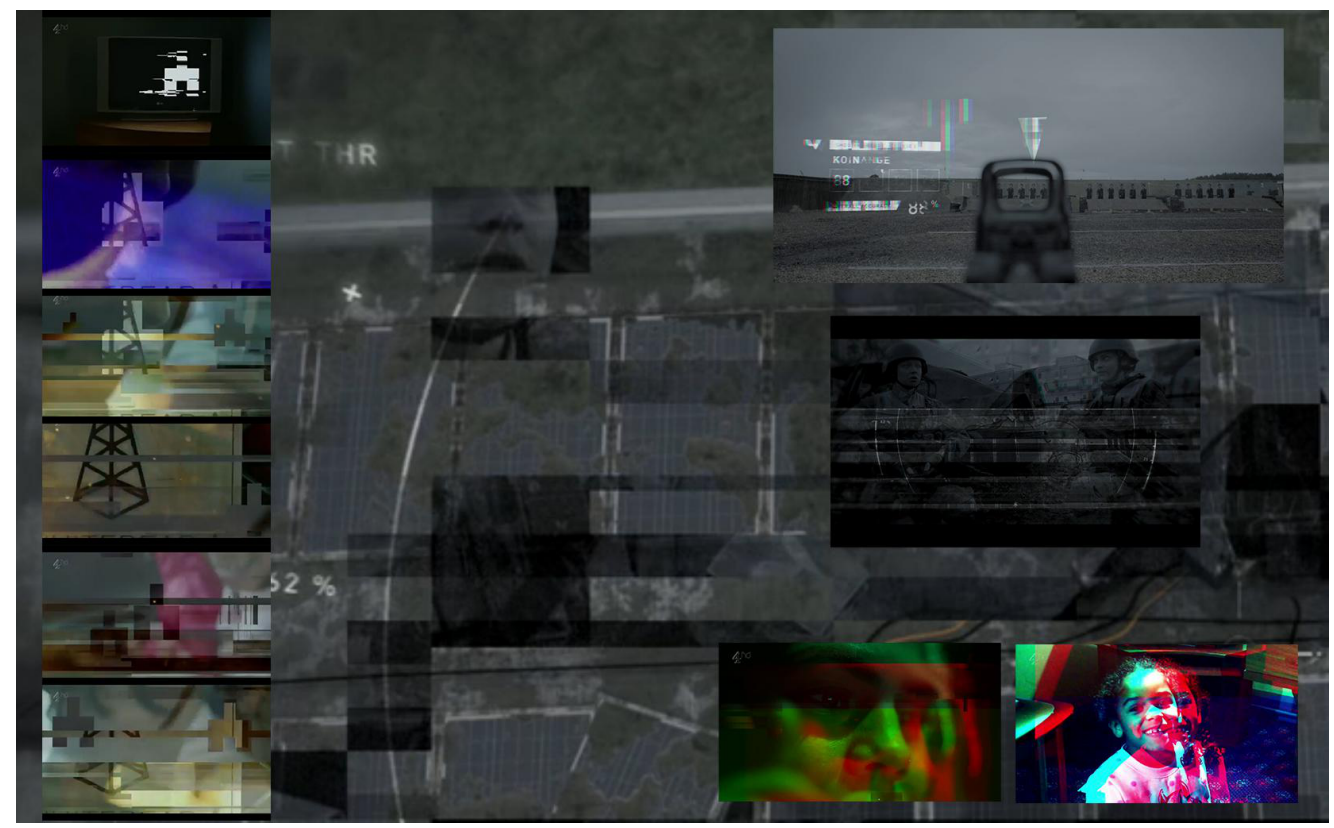

Figura 1. Prancha "Glitch-alike \#1": Montagem com frames (pausa das imagens em movimento) do sintoma Glitch-alike nos episódios "White Bear" (2011) e "Men Against Fire" (2016). Screen Shots realizados em 2017 e 20188.

\footnotetext{
${ }_{7}$ A partir de Darwin ("princípios gerais da expressão"), de Nietzche ("formas afetivas primitivas"), de Burckhardt ("resíduos vitais") e Tylor ("sobrevivências") - conforme apontado por Didi-Huberman (2013).

8 Em 2018 auxiliaram alunos junto à disciplina "Teoria da Imagem" (exercício solicitado em sala-de-aula como parte da didática em ensino-aprendizagem de análise da forma videográfica a partir do método de Aby Warburg).
} 
"Atlas Mnemosyne" é o nome do conjunto de pranchas (design do movimento) utilizado nesse método warbuguiano de montagem visual para análise imagética via fórmulas de afecção que se perpetuam temporalmente (nachleben ). Pode esse princípio também ser utilizado junto às didáticas sobre as cinematografias de ficção científica?

Quando (re)aplicado - 'replicante' - o método à série Black Mirror identificamos, à princípio, três formas compositivas que se repetem egm diferentes episódios como subjetividade corporal das protagonistas auferindo modelos de afecção junto ao espectador:

1. Glitch-alike;

2. A.R. [Realidade Aumentada] e

3. Mask [motion track eyes].

A seguir, alguns experimentos (pranchas) sobre tais gestos que se perpetuam nas estéticas videográficas - dramaturgias da forma híbrida - nesse início do século XXI:

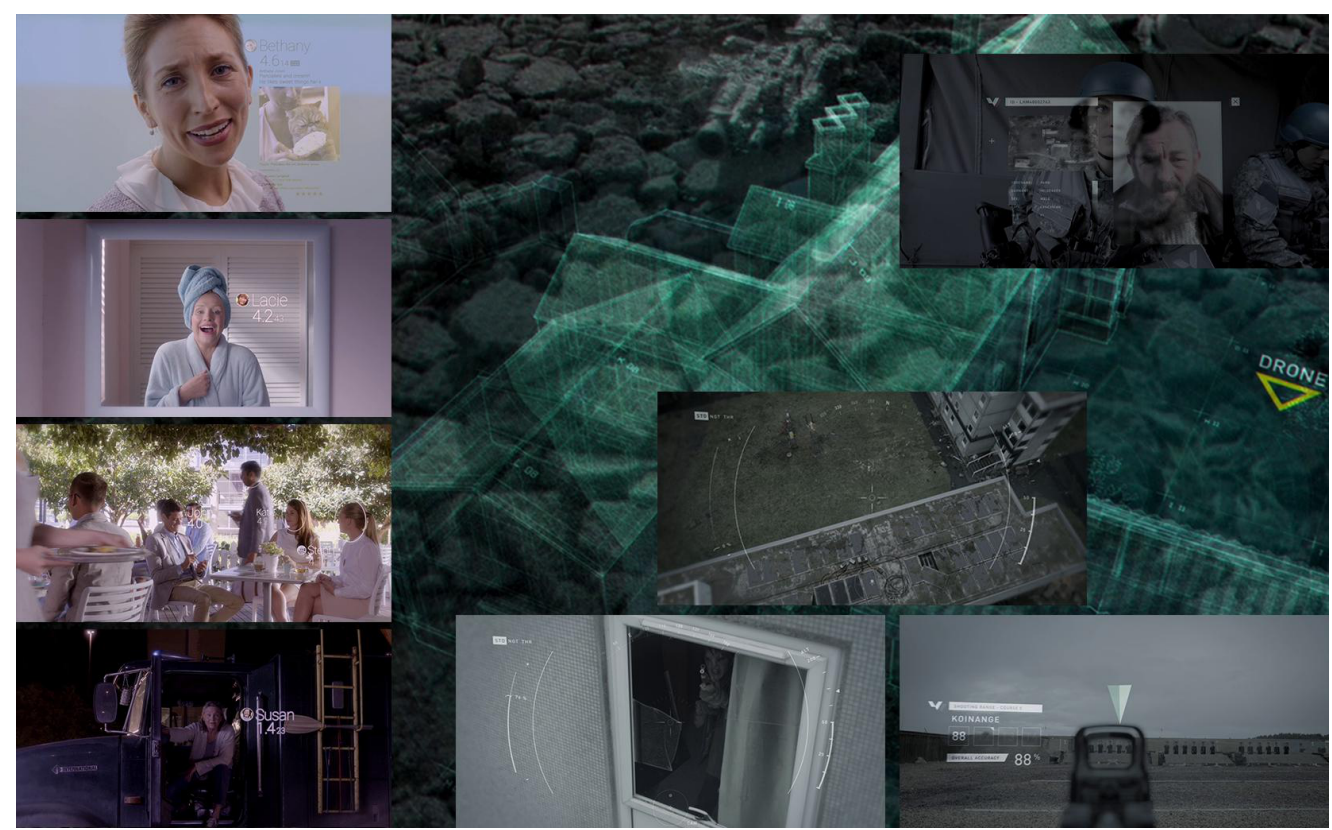

Figura 2. Prancha "Realidade Aumentada \#1": Montagem com frames (pausa das imagens em movimento) das composições com elementos gráficos sobrepostos às live actions afim de desenharem-se os gestos de "Realidade Aumentada" (A.R.) - interfaces - nos episódios "Nosedive" (2012) e "Men Against Fire" (2016). Screen Shots realizados em 2017 e $2018^{9}$. 
A escolha do objeto aqui sob análise - a série Black Mirror - se deu em virtude de compartilhamentos entre meus alunos do curso de Cinema e Audiovisual ao longo das mostras "Futuros Fantásticos: os autômatos sonham com ovelhas tecnológicas?" e "PKD, a ficção científica de Philip K. Dick" (apoio PROGRAD-UFC) - ambas realizações junto à disciplina optativa "Laboratório de Efeitos Especiais" ao longo de dois semestres em $2016^{10}$. Qual o nosso papel como educadores senão compreendermos o mundo audiovisual em que se encontram inseridos nossos estudantes e refletirmos, junto a eles, sobre as escolhas estéticas dessas imagens (e sons) que nos afetam através da montagem?
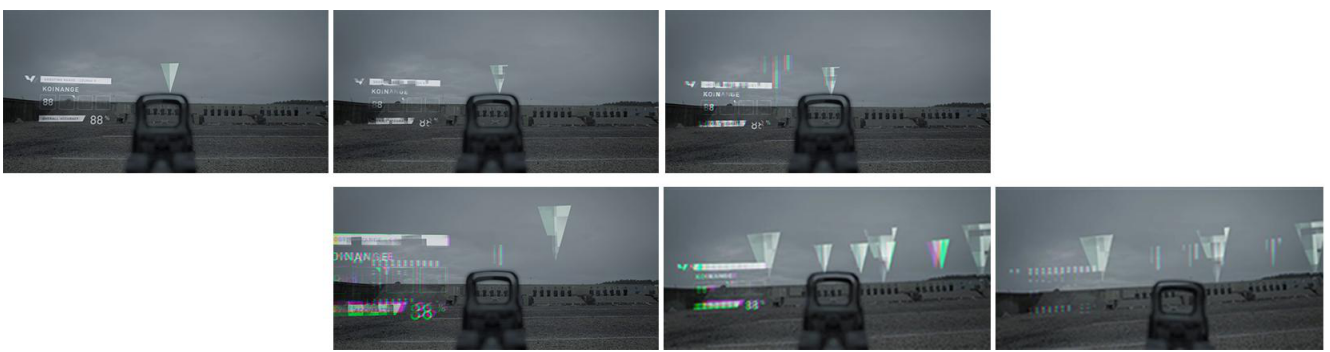

Figura 3. Montagem com frames (pausa das imagens em movimento de 00:18:27:07 a 00:18:28:21; 1seg.15fr) da sequência FPG ${ }^{11}$ também realizada via composição multi-camadas: live action aliado aos elementos gráficos e o sintoma de falha no episódio "Men Against Fire" (2016). Screen Shots realizados em 2017 e $2018^{12}$.

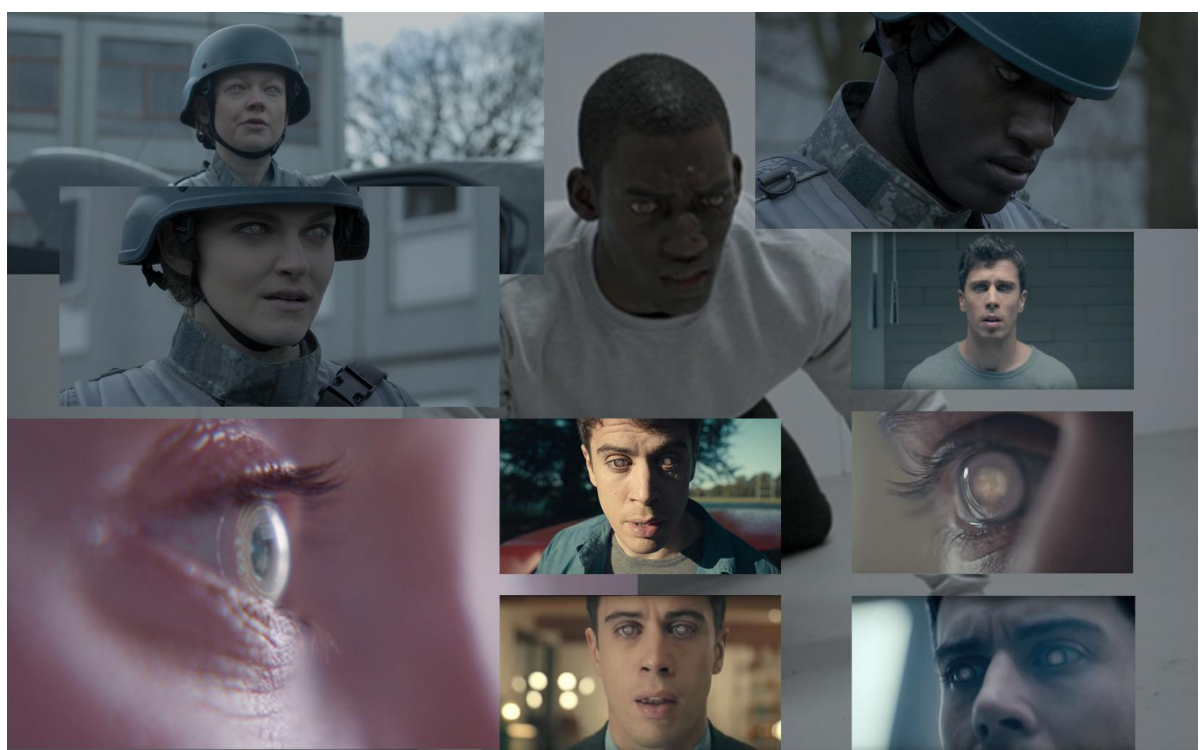

Figura 4. Prancha "Olhos-Mask \#1": Montagem com frames (pausa das imagens em movimento) nos episódios "Nosedive" (2012), "The Entire History of You" () e "Men Against Fire" (2016). Screen Shots realizados em 2017 e $2018^{13}$.

$\overline{10}$ Tratava-se então de minha metodologia-protótipo para a elaboração de uma nova disciplina: "Laboratório de Motion Graphics" que, a meu ver, era uma urgência ao ensino-aprendizagem nas artes audiovisuais.

${ }^{11}$ First Person Game (termo que denomina as câmeras subjetivas nos jogos digitais em primeira pessoa)

${ }^{12}$ Captura sequencial realizada junto aos estudantes lanna Leal e Renan Oliveira.

${ }^{13}$ Em 2018 auxiliaram alunos junto à disciplina "Teoria da Imagem" (exercício solicitado em sala-de-aula como parte da didática em ensino-aprendizagem de análise da forma videográfica a partir do método de Aby Warburg).

ouvirouver Uberlândia v. 14 n. 2 p. 340-360 jul.|dez. 2018 
Ou seja, interessava-me compreender, à época, o segredo fundamental do efeito provocado pela série sobre meus alunos. Ao mergulhar nessa obra "pop" que atraía atenção de toda uma jovem geração também fora do Brasil"14 - debruceime então na hipótese da forma videográfica, de acordo à "Obraznost" de Eisenstein (MICHAUD, 2013), como poder intrínsico à narrativa proposta: a imagem-montagem e seus procedimentos composicionais-sensoriais (design audiovisual).

Assim, convido a mergulharmos juntos nas artes do fazer audiovisual, da imagem em movimento e seus distintos gestos de montagem através da mescla (remix) das lógicas de criação em linguagens pré-existentes. Esclareço que poderíamos, ainda, fazer um caminho através das ferramentas de edição, composição, manipulação ou montagem, onde encontraríamos uma (im)possível linearidade de evolução tecnológica referente aos processos da imagem em movimento.

A linguagem visual que eu estou analisando encontra-se completamente inserida ao nosso redor hoje - talvez isso explique porque os acadêmicos permaneçam cegos frente a isso. [...] Você, por si só, consegue ver todos os exemplos das diversas estéticas que eu mencionarei a seguir, pois trata-se simplesmente de prestar atenção aos grafismos televisivos ou ir a uma boate e assistir à performance de um VJ [visual jockey; live cinema], ou visitar as páginas de designers ou produtoras em efeitos visuais e/ou aos motion graphics na Internet. [...] a partir do momento que meu objetivo é descrever a nova linguagem cultural que, desde agora, se torna praticamente universal, eu quero enfatizar que cada um desses exemplos pode ser substituído por outros tantos mais. (MANOVICH, 2013; grifos meus ${ }^{15}$ )

[trata-se do] meio pictórico cinematográfico - seu uso dinâmico da luz e montagem para criar imagens - como uma forma contemporânea de pintura. Na verdade, existem excêntricos que obstinadamente recusam-se a compreender isso e são totalmente incapazes de aceitar o cinema (esse milagre do potencial pictórico) como parte da corrente principal do desenvolvimento e da história da pintura [e das artes]. Isto me parece profundamente injusto: a diferença da 'technology' é irrelevante. (EISENSTEIN, 1993후; grifos meus)

Sigo, portanto, na busca em decifrarmos a questão sobre quais são os modus operandi dessa escrita, suas formas, suas estéticas, afim de compreendermos que a potencialidade de um estilo está sempre no caminhar desse [m]unido à esté-

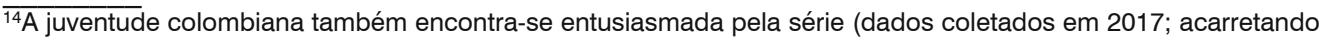
na escrita de uma quarta versão em fevereiro de 2018. Enquanto os britânicos se emocionam com a série distópica brasileira "3\%", dados de agosto de 2018 - o que provavelmente poderá gerar um novo e distinto ensaio sobre o enfoque urbano-tupiniquim: a série foi criada e desenvolvida por uma equipe situada na cidade de São Paulo).

${ }^{15}$ Trecho das traduções ao português de Software Takes Command, realizadas pela autora do presente ensaio e em processo de revisão para publicação acadêmica.

${ }^{16}$ Tradução ao português realizada pelo estudante Renan Oliveira, bolsista "Projet'ares 16Audiovisuais" (20172018) e intergrante do "Intervalos \& Ritmos", grupo de estudos em Estéticas da Montagem Audiovisual [coletivo artístico \#ir!]
} 
tica (a ciência da experiência como ato de afecção tecno-conceitual). O grande desafio está em conseguirmos trabalhar estilo e estética para que as gerações futuras possam dispor, no sentido da cultura, de espírito criticista e sensório.

Para Eisenstein (1993; 2002), a montagem - geradora do choque, da sensação de força dinâmica e impulsiva - é um conjunto entre composição imagética via ideia de simultaneidade (sobreposições na consciência do espectador) aliada ao encadeamento de planos (ideia de movimento). Formato, cor, iluminação, contorno, escala, movimento etc auferem o todo projetual. A montagem, para Eisenstein, ao justapor metáforas, imagens e conceitos significa "a presença conjunta simultânea em uma tela de elementos que são, em essência, as fases sucessivas de todo um processo" (op. cit.). Como no design gráfico, as partes tornam-se inseparáveis do todo. Na busca pela produção de afecção, qual é o segredo fundamental do efeito provocado no espectador através da composição, imagem-montagem?

\begin{abstract}
Muitos foram aqueles que experimentaram o sentimento especial de exaltação e inspiração que dominou o espectador ao ver a pintura original. A pintura apresenta um uso extremamente econômico da cor. É quase arrepiante na severidade de sua pose; é quase grosseiro na sua disposição de massas; [...] Uma única figura preta e vertical, contra um fundo cinza da parede e um espelho. $O$ espelho corta a figura na cintura e reflete um pedaço da parede e do teto que estão opostos da sala vazia em que a atriz foi pintada. No entanto, ao contemplar essa tela, a pessoa é dimensionada para algo da mesma emoção [...] Não é por acaso que me referi ao espelho como a cortar a figura. Para mim, naquele corte e naquele tipo de montagem de justaposição dos resultados do corte reside o segredo fundamental do efeito provocado por este retrato. [...] Os contornos traçados pela primeira linha cerca a figura como um todo; este é um plano aberto. A segunda linha nos dá a 'figura dos joelhos para cima' (plano americano). A terceira, um plano médio. E, finalmente, a quarta linha nos dá um típico 'close-up'." (EISENSTEIN, 1993)
\end{abstract}

Ainda que tenhamos a vanguarda artística junto à imagem em movimento (Richter, Vertov e outros realizadores à década de 1920), a montagem cinematográfica geralmente passava ao largo da superposição (sobreposição) de diferentes imagens dentro de um mesmo quadro (quando ocorria, apenas duas eram colocadas uma sobre a outra de uma maneira bastante padronizada, como letras estáticas aparecendo sobre captações live action ou em imagens estáticas como créditos de abertura nos longas).

A videoarte traz novo fôlego à arte cinematográfica e a imagem em movimento volta a se aventurar nos sistemas estéticos para além da montagem por justaposições temporais. Interessa-nos auferirmos valor estético a dois tangenciais caminhos 'cinemáticos': 1. as composições tipográficas junto aos live actions como parte da narrativa em andamento (experimentações de Godard em alguns de seus filmes à década de 1960 e que se seguirá pelos anos seguintes) e 2. a convite de Otto Prelinger, Elaine e Saul Bass partem, em 1955 (HASKIN, 1996), ao desenvolvi- 
mento de aberturas de filmes via motion graphics.

Naqueles interstícios dos anos 1920 a 1955 lembramos, ainda, um realizador-montador que é uma de nossas principais referências à imagem em movimento sobre questões dos específicos modus operandi entre 'motion graphics' e materialidade própria do meio: Norman McLaren experimentava a complexidade do som atrelado à imagem ao desenhar diretamente sobre a película (NFB, 1951). E, às décadas de 1960 a 1980, novos experimentos da imagem em movimento (como a vanguarda do cinema experimental, da Visual Music, entre outros "nichos") como podemos verificar nos trabalhos de John Whitney, Woody Vasulka e Stan Vanderbeek, por exemplo (YOUNGBLOOD, 1970; SPIELMANN, 2015).

As alterações tecnológicas, mais precisamente o acesso massivo às mídias digitais, fizeram com que Manovich (entre 2007 e 2013) passasse a interrogar sobre as estéticas da atual imagem em movimento: podemos compreender essa nova linguagem híbrida como um tipo de remix numa era de "Remixabilidade Profunda"? representativamente, a ele, iniciada pelo software After Effects (1993-1998). Ou seja, não mais vivemos no "remix típico" - combinações somente de conteúdos de uma mesma mídia ou de mídias distintas (MANOVICH, 2013). Agora, o segredo das imagens em movimento se encontra desde os modus operandi - fluxo-de-trabalho (estratégias e técnicas) de produção específico à Era dos programas - numa montagem audiovisual de objetos intrinsicamente pertencentes à mídia digital. Consequentemente, dá-se uma estética visual alteradora dos parâmetros daquela opacidade e transparência tão caras aos estudos cinematográficos. Essa "nova" estética híbrida significa o combinar tomadas de live action às imagens computadorizadas, aos grafismos, às tipografias animadas etc, independentemente (sem preconceito) do tipo de projeto e do dispositivo de saída (output).

Interessa-nos tais gestos compostitivos projetuais que altera(ra)m nossas estéticas cotidianas e artísticas em vista das discussões sobre montagem nas diferentes artes audiovisuais. Nosso atual debate estético é um nado (des)sincronizado, portanto, em como o cinema (a imagem em movimento) se tornou design; em como o design audiovisual trabalha seus diferentes elementos imagéticos (um plano de live action, uma forma geométrica, um letreiro tipográfico ou uma tipografia animada etc) como formas de escritura. Para tanto, verificaremos brevemente sobre a potência dessa arte da imagem-montagem aplicada como parte estética da forma fílmica (composição videográfica) em Black Mirror. Ou seja, aqui veremos como tais arranjos particulares desses elementos no espaço e no tempo - a montagem-design são o segredo da força afetiva no espectador.

a ficção científica surgiu no século XIX [...] não surgiu somente ligada à ciência, mas relacionada com o ideal de educação que igualmente emergia nesse momento. [...] a ideia nova do século XIX é a da educação para todos, e portanto a comunicação das verdades" (DUFOUR, 2011)

Black Mirror - lançada em 2011 pela BBC, rede pública britânica (para a qual os cidadãos conterrâneos de Bentham necessitam pagar, impreterivelmente, a "Television Fee") - faz parte de um modelo televisivo onde a estrutura seriada difere 
da clássica, onde através de episódios independentes, o fio-condutor é o eixo temático. Ou seja, ainda que tenha como fio-condutor aparente a tecnologia, a distopia e um modelo fabular de "educação para todos", não se trata estritamente de uma ficção científica sobre o futuro, mas possivelmente de nosso atual presente (FULLER, 2016). Dessa maneira, a série Black Mirror está mais ligada aos contos de literatura fantástica naquilo que essa antecede e se encontra à ficção científica: o dissecamento do comportamento humano através da lógica de estranhamento com o familiar (FREUD, [1919]2001).

Esse contínuo tratamento de telas em transmissão (tele-audiovisualidades) sob as que vivemos atualmente parece ser a estética que tece um não-linear encadeamento entre os episódios da série. Estética que é trabalhada na forma fílmica (composição videográfica) através de uma montagem audiovisual com intensa utilização dos motion graphics e efeitos visuais. Na série, forma e conteúdo caminham eisensteinianamente através de cotidianas referências.

\begin{abstract}
Black Mirror é uma exploração satírica da sociedade moderna, especialmente uma que dialoga com as recentes inovações tecnológicas. [...] mas na realidade, a série é mais uma representação da sociedade distribuída conforme descrita por Galloway em "Protocol". O protocolo já não mais é qualquer interação tecnológica, como também passa a sobressair-se no nível social. (Narrative and Technology Blog, 2015; nossa tradução ${ }^{17}$ )
\end{abstract}

Parte importante da forma fílmica, como sabemos, é a montagem do conceito visual. Coodernada, desde o início da série, por Joel Collins - co-fundador da produtora "Paiting Practice", especializada em efeitos especiais e motion graphics -, visa trabalhar esteticamente as visões distópicas de Charlie Brooker (produtor da série). Em entrevista, Collins assume que a utilização de motion graphics como implícito elemento estético à composição videográfica proposta, é uma "stylised version of the way we live now". (STEVEN, 2016)

A "versão estilizada de nosso atual modo de vida" caracteriza-se por um jogo contínuo das Pathosformeln. Três são as composições "híbridas" até o momento mapeadas (acima listadas) que permeiam diferentes episódios na série. Composições audiovisuais via glitch-alike (MORADI, 2004), por exemplo, podem ser encontradas em "White Bear" (2011; episódio 2 da 2a temporada ainda sob a produção do "Channel 4") e em "Men Against Fire" (2016; episódio 5 da 3a temporada; primeira temporada então realizada junto à Netflix) -conforme vemos na prancha à Figura 1.

Nesse segundo episódio de 2011 (“Urso Branco") o design audiovisual - na estética dos ruídos e flicagens em RGB - como gesto-forma disparadora da memória da protagonista ("flickers of memory") - sugere uma relação direta com a mnemônica (YATES, 2007). Ou seja, o desencadeamento emotivo na personagem, a partir de uma imagem via estética glitch-alike - proposta às imagens subjetivas da

\footnotetext{
$\overline{17}$ No original: "Black Mirror is a satirical exploration of modern society, especially that which deals with recent technological innovations. [...] but in reality it is a better representation of the distributed society that Galloway describes in Protocol. The protocol is no longer some technological interaction, but begins to emerge at the social level as well"
} 
protagonista (corporeidade do sintoma) - é gerado por um signo típico (significância do sintoma) na cultura digital: linkagem, memória, vigilância, rastreamento e controle. Nessa narratividade e composição sonoro-imagética em primeira pessoa, ao se trabalhar conjuntamente o gesto da flicagem, visa-se produzir "efeitos sensoriais imediatos" no espectador. Mescla-se, assim, o ruído próprio de uma materialidade original específica (a flicagem pelicular) afim de significar a ideia de que "a exibição imagética não mais é a reconstituição da gravação", como afirmara Paul Sharits (MICHAUD, 2014) ao trabahar diretamente na materialidade ao longo de seus experimentais flicker films (1960-1976).

Se estabelecermos uma "iconologia dos intervalos" a essa nossa análise da composição videográfica na série, esse gesto de imagem-montagem retorna no episódio "Men Against Fire". Novamente a estética glitch-alike encontra-se presente, mas agora de duas maneiras distintas: 1. como ruídos de memória (no caso, o sonho) combinados em uma montagem de flicagens (travamento da projeção) através do scratch temporal aliado à repetição imagética; 2. as falhas em RGB agora auferem a falhas próprias ao sistema visual (quando então os pixels aparecem e desconstróem as "reais" imagens subjetivas do soldado).

Nol Carroll (REDFERN, s/d) distingue dois diferentes modos de se estudar a forma cinemática: a funcional e a descritiva. Sabemos que a forma de um filme é a "junção de escolhas" que visa alcançar propósitos implícitos à obra. O modo funcional caracteriza-se pelo carácter seletivo que evita a generalidade do modo descritivo, focando-se naquilo que é importante e que, dessa maneira, ilumina nossa compreensão da forma fílmica. A análise funcional não apenas descreve o filme, mas sim explica o porque ele é dessa maneira. Assim, as decisões estéticas são feitas dentro de contextos específicos - "the relationship between the form ('how') and content ('what') of a film". Encontramos mais alguns gestos, via imagem-montagem, característicos da série, onde animações e informações textuais se mesclam às imagens live action da câmera subjetiva. O que significa que o estilo, como estética, torna-se o coração de um processo composicional a essa articulação crítico-sensorial ${ }^{18}$.

Black Mirror (obra tele-audiovisual futuro do pretérito) joga com o que podemos denominar ser uma "estética do olhar", naquilo que essa possui de mais "aterrorizante" (BURKE, 1998) entre a automação do ser humano ao "aparatizar" o olhar para decorrente 'scaneamento' dos olhos - informações lidas em tempo real, bancos-de-dados em streaming (re)acessados e a "arquitetura" sinóptica em nossa sociedade neo-panóptica. Outro gesto na série é o olho transformado em um dispositivo automatizado. Quando "mascarado", corta-se o plano da personagem para composições videográficas a partir de motion graphics sobrepostos a câmeras subjetivas - o que traduz "cinematograficamente" as interfaces gráficas aos usuários, possibilidades de utilizações possíveis em "realidade aumentada" (R.A.; conforme Figura 2) mescladas a esquemas próprios de "realidades virtuais" (V.R.) no cotidiano do futuro presente.

Trata-se de certa "hipnose" entre jogos de raccord que buscam situar e localizar o espectador, preparando-o sob um ponto de vista dramático nesse jogo de

\footnotetext{
18 Ver o vídeo-artigo "Design Audiovisual, Ensaio 10min.". Trata-se da análise da vinheta de abertura em Black Mirror através da leitura do trecho inicial do artigo "Cinema como Design: a montagem (tele-)audiovisual de Black Mirror" (minha 5a versão sobre estética e estilo na série) < https://youtu.be/bqZiULrhm5A >, acesso em 18/9/18.
} 
montagem audiovisual à narrativa proposta. Nessa lógica de montagem, verificamos a utilização intensiva de diversos recursos (efeitos) de motion track - geração de movimento do grafismo sobre o live action que alude às tecnologias de "realidade aumentada" (ver Figura 3). Essa aposta compositiva à montagem audiovisual - estéticas do design gráfico em movimento aliado às live action de câmera subjetiva (como nas estéticas dos jogos em primeira pessoa; FPG) -, permeia diversos planos, significando a busca por reforçar o diálogo entre público e subjetividade narrativa (corporeidade dos sintomas). Leocádio Nova (2009) sugere, ainda, que "[n]esse artifício de construção, que só existe na tela, obtemos uma composição de imagem com uma profundidade [de campo] distinta daquela observada nos estudos ontológicos da imagem cinematográfica." Ou seja, expande-se o conceito eisensteiniano de "mise-en-cadre" (dramaturgia da forma), quando agora a composição dá-se também através de motion graphics onde tais "componentes visuais, [e] seus arranjos" tornam-se "um elemento a mais [ou principal] na encenação fílmica. [...] enunciando novos significados para as trucagens cinematográficas." (NOVA, 2009)

Ainda no episódio "Engenharia Reversa" (título em português de "Men Against Fire"), quando as falhas imagéticas começam a operar na visão subjetiva do protagonista, os diálogos ao longo da sequência entre o médico-psicólogo e o soldado-protagonista trabalham tal filtro sob a nomenclatura "máscara". Mascara-se a relação com o outro - naquilo que esse outro tem de Unheimlich (FREUD, [1919]2001) - como princípio da utilização de um aparato tecnológico (e científico) ao "olhar humano" tal qual em "O Homem de Areia", de E.T.A. Hoffmann. A nomenclatura a tal filtro tecnológico torna esse episódio ainda mais interessante como um convite reflexivo ao espectador através de uma proposta metalinguística: "máscara" é exatamente o nome dado a essa função técnica combinada ao motion track quando da utilização do software After Effects (Adobe) para aplicação dos efeitos visuais ao longo dos episódios.

Episódios como "Men Against Fire", "The Entire History of You" e "Nosedive", entre outros, possuem similares gestualidades à imagem-montagem que, ao trabalharem de diversas maneiras tal corporeidade do sintoma - como o gesto do "olhar mascarado" (ver Figura 4) -, traduzem a literatura fantástica e a ficção científica através de uma fórmula da paixão que se perpetua nas filmografias ao longo da história do cinema (e dos imagéticos, além imaginários, sócio-culturais). Tais composições imagéticas são ora construídas desde o olho embaçado (ausência da íris, na significância sintomática das personagens a quase-cyborgs ${ }^{19}$ ) - caso dos dois primeiros citados -, às alusões das tecnologias em "realidade aumentada" - presentes tanto em "Engenharia Reversa" como em "Queda Livre" (título em português de "Nosedive").

A fórmula sequencial de montagem às composições imagéticas permeia todos os episódios: justaposição temporal através de primeiros planos e contra-planos detalhes entre a personagem, seus olhos e a câmera subjetiva. Tais gestos de montagem aludem à imersão do espectador na narrativa proposta dos olhos ao espaço reflexivo (em duplo sentido). Na segunda análise de "Nosedive", então já no primeiro semestre de 2017, um dos alunos da turma de montagem e edição indagara: "seria a sequência uma impressão da realidade ou o 'real' do reflexo proposto"?

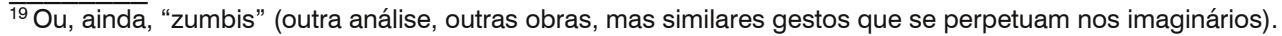


As cores e disposições dos elementos nas composições aos diferentes episódios traduzem também as intenções propostas: "Engenharia Reversa" encontrase, em $65 \%$ de sua duração, sob tons frios - como o verde e o azul com seus matizes dessaturados -, o que induz o espetador a um distanciamento (DONDIS, 1991). Já "Nosedive" opera através de tons pastéis ao longo de $90 \%$ de sua duração, visando a pacificação das paixões, onde nada parece ser pró-revolta ou visceral (uma estética hipster-indie ou neo-bossa nova típica desse nosso início da década de 2010).

\section{Movimento\#3}

A Cosmococa foi conceituada por Hélio Oiticica (junto a Neville D'Almeida) para "inovar o tradicional cinema brasileiro". Aqui, o espectador torna-se participador. (SZAFIR, 2015)

Cinema é uma palavra grega que significa movimento. A ilusão do movimento é, sem dúvida, o complemento habitual da imagem cinematográfica [...] Doravante, chamaremos nossa arte, simplesmente, de "o cinema" (FRAMPTON apud MICHAUD, 2014)

A montagem audiovisual é costumeiramente associada à edição cinematográfica. Ao longo dos últimos cem anos - aproximadamente o período em que se iniciam as teorias cinematográficas (da "nova mídia" à época), compreensão do cinema como uma linguagem -, a montagem audiovisual não apenas pode ser encontrada em distintas estéticas da imagem em movimento, como torna-se o fundamental de toda obra-de-arte (BENJAMIN, 1988).

Distintas são as maneiras de montagem e, defendo, devem ser desenvolvidas visando o projeto como um todo (o que significa que todo 'design' almeja a um determinado projetar: a imagem e som trabalhados já em vista de distintos dispositivos de exibição). Por exemplo, já no início do cinema podemos citar Abel Gance que desenvolveu uma montagem cinematográfica destinada a projetar-se em três telas simultâneas ("Napoleão", 1927).

Ainda que ao longo do século passado (até nossos dias atuais em que aqui Ihes escrevo) a montagem cinematográfica passou a ser considerada uma etapa meramente técnica destinada à manipulação da imagem (e do som) - que serve tão somente ao encadeamento preciso dos planos sob domínio do roteiro, diretor e produtor -, lembramos que à década de 1920 essa "nova mídia" era de diversas maneiras experimentada. Walter Ruttman, Oskar Fischinger e Viking Eggeling, por exemplo, desenvolviam uma arte cinética abstrata tal qual Hans Richter (nesse último podemos encontrar filmes-ensaios via composições imagéticas e tipográficas que se sobrepunham - como "Inflation", 1928, ou "Ghosts Before Breakfast", 1927). Vertov - junto ao coletivo Kinoks - apostava em uma montagem através dos intervalos como também de efeitos visuais calcados na manipulação do plano-sobreplano e da metalinguagem ("Homem com uma câmera", 1929), Duchamp operava através de uma montagem sensorial ("Anemic Cinema", 1926) tal qual seus conterrâneos Léger e Murphy ("Ballet Mechanique", 1924). Nos EUA, Griffith desenvolvera 
a lógica da opacidade através da montagem (1915), regras utilizadas também por Protazanov ao realizar o primeiro filme soviético no gênero ficção científica ("Aelita", 1924) - trabalhando sua estética através da direção-de-arte construtivista entre cenários e figurinos. Também a montagem através de "trucagens" (pós-Méliès; "A Trip to the Moon", 1902) pode ser encontrada em Fritz Lang quando inserira "efeitos especiais" no primeiro filme da trilogia do Dr. Mabuse (1922), ainda que seja um realizador mais associado à estética impressionista cinematográfica alemã. Eisenstein, como sabemos, encontrava-se em diálogo entre a teatralidade de Brecht e os ideogramas japoneses ${ }^{20}$ (como em "Encoraçado Potemkin", 1925, por exemplo). Nessa lógica eisensteiniana de montagem, podemos dizer que Buñuel traduzia o surrealismo na imagem em movimento ("O Cão Andaluz, 1929). No entanto, muitos foram os cineastas que estiveram "fora-da-regra" e, meio século depois, o cinema experimental retoma a importância da montagem com Paul Sharits, Peter Kubelka e Tony Conrad, entre outros (SMITH, 2009). Paralelamente, a montagem audiovisual encontra no found footage (WEES, 1993) um êxito de sua existência.

O vídeo - entre a televisão e a videoarte - passa a operar a montagem intrínsica à lógica da captação ao vivo (cortes secos de uma câmera a outra por meio de uma botoneira ou fade in/out via manivela) e dos circuitos fechados de tv (CCTV) - como vemos nos trabalhos de artistas como Nauman ("Corridor", 1968-1970), por exemplo. O vídeo, como estado artístico da imagem em movimento, passa a operar portanto também em distintos ambientes: da performance ao teatro, do cinema expandido às instalações videográficas (RUSH, 2006). Ao se instaurar a possibilidade de gravações (VTs) aliadas aos "mixers", um novo fôlego criativo é introduzido dentro da montagem audiovisual como manipulação de transições, split-screen, chroma e lumakey: a composição eletrônica da imagem em movimento - como, por exemplo, vemos nos trabalhos de Nam June Paik, ("Global Groove", 1973), Zbigniew (“Tango", 1980), Sandra Kogut ("Parabolic People”, 1991) e Godard ("Histoires du Cinema”, 1998), entre outros artistas audiovisuais dentro e fora do Brasil. O que se vê é a videomixagem como um processo de não-linearidade além justaposição, um trabalho de sobreposição de camadas - a multiplicidade da imagem na imagem -, como Fargier refletira a respeito desde obras de Averty (DUBOIS, 2004).

Às décadas de 1990 e 2000, jovens artistas retomam todo o sistema de montagem audiovisual televisiva - ilhas-de-edição destinadas aos cortes das câmeras ao vivo e/ou manipulações imagéticas no tempo real - e passam às experimentações videográficas em espaços de música (são os chamados visual jockeys) na esteira da era eletrônica (Djs) e das artes visuais (collage, pastiche, approppriation "some artists were making references to 'modern and avantgardist techniques, forms and images'”), dando início à cultura digital (com suas distintas lógicas de interatividade aplicadas à montagem audiovisual, e vice-versa). Os computadores, ao se tornarem acessíveis como "personal", transformaram-se em verdadeiros aparatos de escrituras audiovisuais, conforme Chris Marker e Marcelo Masagão apontaram à década de 1990 (SZAFIR, 2015).

Termos como ritmo, métrica, intervalos etc - originalmente parâmetros instituídos (e operacionalizados) pela teoria e linguagem musical - tornaram-se a base da montagem, como sabemos (seja ela cinematográfica, videográfica ou imago-his-

\footnotetext{
$\overline{{ }^{20} \mathrm{Hoje}, \mathrm{um}}$ século depois, visualizamos os ideogramas chineses para, talvez, também potencializarmos junto à montagem suas lógicas de produção e criação - mas esse já é outro enfoque projetual...
} 
toriográfica). Ao aceitarmos a hibridização da imagem em movimento, causada tanto pela "Remixabilidade Profunda" quanto pelo seu alcance em distintos nichos culturais e estéticos da(s) sociedade(s), podemos enfim afirmar (sem medo!) que infinitos são os movimentos audiovisuais que formam essa composição. Ou, qual o papel da sintaxe visual no ensino-aprendizagem da estética na montagem audiovisual em tempos de "novas mídias"?

Rob Walker, crítico de design, argumenta que a série não é sobre o medo das tecnologias futuras. Não se trata de um mundo (um futuro ou uma realidade alternativa?) onde a tecnologia vai para o lado errado e ganha muito poder, mas sim sobre como as pessoas utilizam mal tal tecnologia com a qual interagem. [Brooker, o produtor de Black Mirror] tem dito que se trata de uma série sobre 'pessoas fracas utilizando poderosas ferramentas' [...] quando você assiste à série através dessa lente, ela se torna algo menos sobre futuros distópicos e os abusos tecológicos e mais sobre nosso próprio mundo - aqui e agora -, como nós interagimos com ele. Black Mirror é uma história sobre design. [...] o crescimento de campos conhecidos como 'design fiction', 'speculative design' e 'critical design' [... "Então os professores podem - ou devem - utilizar] o design para estimularem a discussão e o debate $[\ldots]$ sobre as implicações éticas, sociais e culturais das já existentes tecnologias e das emergentes." [...] para especularmos sobre um futuro possível, para criticarmos histórias sobre a atual cultura ou usarmos o design gráfico para contarmos ficções sobre a sociedade, a política, a tecnologia e a cultura. (FULLER, 2016; grifos meus21)

Portanto, quando a imagem em movimento invade todos os âmbitos da arte e da cultura, eu gostaria de reiterar a necessidade de darmos a devida importância à montagem não como uma "pós-produção" ou mera (necessária) habilidade técnica, mas sim como uma verdadeira experiência de escritura e pensamento - no original sentido de aesthesis: um espaço e temporalidade de composição da(s) arte(s), a experimentação da montagem audiovisual como design, o projetar artístico em sua complexidade tecnológica, social, política e cultural.

\section{Referências}

ARTIGAS, Vilanova. O Desenho. São Paulo: Centro de Estudos Brasileiros do Grêmio da FAU-USP, 1975. Disponível em: < https://www.archdaily.com.br/br/790124/o-desenho-vilanova-artigas > ou < https://issuu.com/itaucultural/docs/ocupacaoartigas_aulaodesenho > Acessos: 08 abril 2018; 06 junho 2018.

\footnotetext{
${ }^{21}$ No original: "The design critic Rob Walker argues that the show is not about fear of future technologies. It's not about a world (a future? an alternate reality?) where technology goes wrong and gains too much power, but rather about how people who interact with this technology misuse it. [Brooker] has called it a show about 'weak people using powerful tools' [...] When you view the show through this lens, it's less about dystopian futures and the abuses of technology and more about our world - here, now - and how we interact with it. Black Mirror is a story about design. [...] the growing fields known as 'design fiction', 'speculative design', and 'critical design' [...] '[Então professores podem - ou devem - usar o] design to stimulate discussion and debate [...] about the social, cultural and ethical implications of existing and emerging technologies.' [...] to speculate about a possible future, critique stories about current culture, or use graphic design to narrate fictions about society, politics, technology, and culture."
} 
BENJAMIN, Walter. Magia e técnica, arte e política: ensaios sobre literatura e histórias da cultura: obras escolhidas: volume 1. São Paulo: Brasiliense, 1993.

BLUMLINGER, Christa. "Incisive divides and revolving images: on the installation Schnittstelle. In: ELSAESSER, Thomas (org). Harun Farocki - working on the sightlines. Amsterdam University Press, 2004.

BURKE, Edmund. A Philosophical Enquiry into the Origins of the Sublime and Beautiful. New York: Penguin, 1998.

DEWITT, Tom. "Visual music: searching for an aesthetic". Leonardo, Vol. 20, N. 2, pp. 115-122, 1987. Disponível em: < http://staff.pccu.edu.tw/ tdl/VisualMusic.pdf > Acesso: 15 dezembro 2016.

DIDI-HUBERMAN, Georges. A imagem sobrevivente: história da arte e tempo dos fantasmas segundo Aby Warburg. Rio de Janeiro: Contraponto, 2013.

DONDIS, Donis. Sintaxe da linguagem visual. São Paulo: Martins Fontes, 1991.

DUBOIS, Phillipe. Cinema, vídeo, Godard. São Paulo: Cosac Naify, 2004.

DUFOUR, Éric. O cinema de ficção científica. Lisboa: Edições Texto\&Grafia, 2012.

EISENSTEIN, Sergei. The film sense. Harcourt, Brace and Company: NY, 1942.

EISENSTEIN, Sergei. A Forma do filme. Rio de Janeiro: Jorge Zahar, 1990.

EISENSTEIN, Sergei. O Sentido do filme. Rio de Janeiro: Jorge Zahar, 2002.

EISENSTEIN, Sergei. "Tekstura”. In: EFIMOVA, Alla; MANOVICH, Lev (organização e tradução). Russian Essays on Visual Culture. Chicago Press, 1993, p. 10-36.

FAROCKI, Harun. Schnittstelle [instalação ou vídeo "single image"]. Junho, 1995. Disponível em: < https://www.imdb.com/title/tt0269834/ > e < https://www.youtube.com/watch?v=OrvISbRiSUw > Acessos: 25 outubro 2014; 18 outubro 2018.

FREUD, Sigmund. "The Uncanny". In: The Standard Edition of the Complete Psychological Works of Sigmund Freud, Volume XVII (1917-1919). UK: Random House. 2001[1919], p. 217-256.

FULLER, Jarrett. Black Mirror and design fiction. 2016. Disponível em < http://jarrettfuller.tumblr.com/post/152070390277/black-mirror-and-design-fiction > Acesso: 27 novembro 2016.

GINZBURG, Carlo. Medo, reverência, terror. São Paulo: Companhia das Letras, 2014.

HASKIN, Pamela. "Saul, can you make me a title?: interview with Saul Bass". Film Quarterly, 1996, 50(1), p. 10-17. Disponível em: < http://fq.ucpress.edu/content/50/1/10 > Acesso: 17 abril 2017. 
HOFFMANN, Ernst Theodor Amadeus. Contos fantásticos: o vaso de ouro, os autômatos, o homem da areia. Rio de Janeiro: Imago, 1993.

LIEBMAN, Stuart. Paul Sharits: filmmakers filming. Monografia - Film In The Cities and Walker Art Center: Minnesota State, 1981. Disponível em: < http://www.vasulka.org/archive/4-20b/Sharits(3005).pdf > Acesso: 18 outubro 2018.

MANOVICH, Lev. Software Takes Command. New York: Bloomsbury Academic, 2013.

MANOVICH, Lev. Software Takes Command. 2008. Disponível em: < http://softwarestudies.com/softbook/manovich_softbook_11_20_2008.pdf > Acesso: 26 fevereiro 2018.

MANOVICH, Lev. "After Effects, or Velvet Revolution". Artifact, Volume I, Issue 2, 2007, p. 67-75. Disponível em: < https://scholarworks.iu.edu/journals-old/index.php/artifact/article/view/1357 > Acesso: 15 dezembro 2016.

MANOVICH, Lev. The Language of New Media. Cambridge: MIT Press, 2001.

MCLAREN, Norman; BATCHELOR, Lorne; PETER, Dom. The pen percussion: an introduction to the hand-drawn sounds of Norman McLaren. Montreal: National Film Board [NFB] of Canada, 1951. Disponível em: < https://www.youtube.com/watch?v=Q0vgZv_JWfM > ou < https://www.nfb.ca/directors/norman-mclaren/ > Acessos: 22 setembro 2008; 16 outubro 2018.

MICHAUD, Phillipe-Alain. Aby Warburg e a imagem em movimento. Rio de Janeiro: Contraponto, 2013.

MICHAUD, Phillipe-Alain. Filme: por uma teoria expandida do cinema. Rio de Janeiro: Contraponto, 2014.

MORADI, Irman. Glitch Aesthetics. Monografia (Bacharelado) - School of Design Technology (Department of Architecture), Huddersfield, 2004. Disponível em: < http://www.oculasm.org > ou < http://www.organised.info/wp-content/uploads/2016/08/Moradi-Iman-2004-Glitch-Aesthetics.pdf > Acessos: 23 janeiro 2015; 18 outubro 2018.

NOVA, Leocádio. A dramaturgia da forma das trucagens eletrônicas digitais em Peter Greenaway. Tese (Doutorado) - Escola de Comunicações e Artes USP, São Paulo, 2009.

REDFEN, Nick. "Exploratory data analysis and film form: The editing structure of slasher films". Post Script: Essays in Film and the Humanities, verão de 2015, Vol.34, N.2-3, p. 71-83. Disponível em < https://nickredfern.wordpress.com/ > Acesso: 06 dezembro 2016.

RUSH, Michael. Novas mídias na arte contemporânea. São Paulo: Martins Fontes, 2006.

STEVEN, Rachael. Black Mirror production designer Joel Collins on bringing Charlie Brooker's dystopian visions to life: an interview. 2016. Disponível em < https://www.creativereview.co.uk/designing- 
black-mirror-interview-production-designer-joel-collins/ > Acesso: 27 novembro 2016.

SMITH, William. "A concrete experience of nothing: Paul Sharits's flicker films". RES: Anthropology and Aesthetics. Spring - Autumn, 2009; No. 55/56 , pp. 279-2932009. Disponível em: < https://www.journals.uchicago.edu/doi/abs/10.1086/RESvn1ms25608849?journalCode=res > Acesso: 18 outubro 2018.

SPIELMANN, Yvonne. "Conceptual synchronicity: intermedial encounters between film, video and computer”. Aniki, vol. 2, n. 1, 2015, p. 8-20. Disponível em: < http://aim.org.pt/ojs/index.php/revista/article/view/125/pdf > Acesso: 27 dezembro 2015.

SZAFIR, Milena. Retóricas Audiovisuais 2.1: ensino e aprendizagem compartilhada: passado, presente, futuro: ou uma arqueologia-cartografia da montagem. Tese (Doutorado) - Escola de Comunicações e Artes USP, São Paulo, 2015.

SZAFIR, Milena. "Montagens audiovisuais extra-apropriação: por uma pedagogia do filme-ensaio na cultura digital”. In: Brandão, Alessandra; Sousa, Ramayana (org.) A Sobrevivência das Imagens. Campinas: Papirus, 2015.

SZAFIR, Milena. Retóricas Audiovisuais e o filme Tropa de Elite na cultura em rede. Dissertação (mestrado) - Escola de Comunicações e Artes USP, São Paulo, 2010.

WEES, William. Recycled images: the art and politics of found footage films. New York: Anthology Film Archives, 1993.

YATES, Francis. A Arte da Memória. São Paulo: Ed. Unicamp, 2007.

YOUNGBLOOD, Gene. Expanded Cinema. 1970. Disponível em: < http://www.ubu.com/historical/youngblood/expanded_cinema.pdf > Acesso: 10 setembro 2012.

Recebido em 29/10/2018 - Aprovado em 15/11/2018

Como citar :

SZAFIR, M. Composição: Ensaio em 03 Movimentos. ouvirOUver. Uberlândia, v.14,n.2, p.340-360, jul./dez. 2018. Disponível em: http://www.seer.ufu.br/index.php/ouvirouver; DOI:http://doi.org/10.14393/OUV23-v14n2a2018-7

(c) (i) (8) A revista ouvirOUver está licenciada com uma Licença EY NC Creative Commons Atribuição-NãoComercial 4.0 Internacional. 